\title{
EFFECT OF BERYLLIUM TRACE ADDITION ON THE DYNAMIC SCC BEHAVIOR OF AGED ALUMINIUM-5\% ZINC-4\% MAGNESIUM ALLOY
}

P. Gopalan*, E. S. Dwarakadasa** and Kishore** $*$ Foundry and Forge Division, Hindustan Aeronautics Limited, Bungulore 560.017, India
$* *$ Department of Metallurgy, Indian Institute of Science, Bangalore 560.012, India

ABSTRACT

The dynamic SCC hehavior of a high strength Al-5\% Zn-4\% Mg-0.01\% Be alloy has been studied in $3.5 \% \mathrm{NaCl}$ solution using a slow strain rate tensile testing set-up. The influence of the presence of berylium in trace quantities is most significant in the peak-aged condition and not in the under-aged or overmost significant in the praition, avoidance aged conditions. brings a prout a transgranular ductile fracture and increases toughness and resistance to dynamic SCC.

\section{KEYWORDS}

SCC, Dynamic, PFZ, precipitation, trace element, brittle, ductile, fractograph INTRODUCTION

Among the aluminium based age-hardenable alloys, the Al- $\mathrm{Zn}-\mathrm{Mg}$ system is known to cffer compositions that develop the highest strength (Mondolfo, 1976). However, these alloys suffer from the disadvantage of high susceptibility to compts (Day, Cornish and Dent, 1969; Latanson and Stahele, 1967; Neilson, 1970: Parkins, 1964; Polmear, 1960; Pugh and Jones, 1961; Sedericks, Slattery and Pugh, 1969 Thomas and Nutting, 1959) to correlate this behavior with the structure and composition of the grain boundary region. There also exists a certain amount of disagreement about the origin and mechanism of SCC in these high strength alloys. Most explanations are based on the role of either the grain boundary seen aimed at been aijal treatments or by compositional variations. A singular effort has been the control of microstructure through trace elemental additions. Such additions bring about a change in the precipitate size, morphology and distribution. Since SCC behavior is markedly influenced by the nature and distribution of precipitates, the trace element addition must also exert an influence on the SCC behavior of the alloy.

In the Al- $\mathrm{Zn}-\mathrm{Mg}$ system, it has been found that if the $\mathrm{Zn+Mg}$ content of the alloys is ca. $9 \%$, they develop good strength as well as resistance to SCC 
(Polmear and Sargent, 1963: Ryum, Haegland and Lindtveit, 1967). While copper additions have proved futile in this regard, silver additions are ver and Calvert. Cleam and Cudd, 1971; Davies, 1968; Peters, 1971. Truscot quent studies have revealially in minimizing the occurence of PFZ. Subseabout a similar influence, including In a more recent study(Chandrasekar, 1973) it manganese, indium and zirconio beryllium and boron bring about a significant change in that the elements $\mathrm{A} 7-\mathrm{Cu}, \mathrm{A} 7-\mathrm{Mg}_{2} \mathrm{Si}$ and such other aluminium based extent and nature of the influence of beryllium addition had not b. The in the ternary Al- $\mathrm{Zn}-\mathrm{Mg}$ system. It has been reported had not been studied a large binding energy(Dwarakadasa, 1970) with vacancies in berylium exhibi A1so it has been shown that the presence of beryllium shanged thinium matrix. brittle fracture into a transgranular ductile one in aged Al- the intergranul (Narendranath, 1980). Beryllium also considera in aged Al-Zn-Mg alloys the processed alloy. Thus there existed sufficient indications to soint in possible influence on the precipitate morphology due to beryllium addition in the aged Al-Zn-Mg alloys. This project was therefore taken up to adu the dynamic SCC behavior of an A7uminium-5\% Zinc-4\% Magnesium ap toy study communication.

MATERIALS AND EXPERIMENTAL PROCEDURE

Large blocks of $\mathrm{A} 7-5 \% \mathrm{Zn}-4 \% \mathrm{Mg}$ (base alloy) and $\mathrm{A} 7-5 \% \mathrm{Zn}-4 \% \mathrm{Mg}-0.01 \% \mathrm{Be}$ (Be-containing alloy) alloys were cast, hot forged and then hot $10170.01 \% \mathrm{Be}$ (Be-con$1 \mathrm{~mm}$ thick as per procedure described earlier(Narendranath, 1980). Tensile $20 \mathrm{~mm}$. Solutionizing from the annealed sheets to have a gauge length of extensive study (Narendrana ageing conditions were obtained from an earlier at $570^{\circ}$ or at $460^{\circ} \mathrm{C}$ werenath, 1980). Samples solutionized for $1 \mathrm{hr}$ either $160^{\circ} \mathrm{C}$ for different weris quenched into an iced water bath and then aged at and over-aged conditions. dried before mounting on to the SCC set-imens were polished, degreased and were conducted on a hard tensile testing. Tests for dynamic SCC behavior technique. Strain rates were varing machine using a slow strain rate ous deaerated $3.5 \% \mathrm{NaCl}$ solution ( $\mathrm{pH}=5.2$ and range $10^{-6}$ to $10^{-3} \mathrm{sec}^{-1}$. Aqueclean laboratory air were the environ 2 and temperature $25^{\circ} \mathrm{C}$ constant) and the vicinity of the test set-up varied in the range The relative humidity in course of the tests. All the specimens the range of $75-80 \%$ during the occurred, while automatically recording were tested until complete fracture chart recorder, to enable the evaluation of lidimatongation curve on a strip Per Cent Elongation(\% E1) and the Fracture was calculated as the total area under the stress-strain The fracture energy specimens fractured, the two pieces of the fractured into the chamber of a Cambridge Stereoscan SEl mode1 S-150, to transferre fractographic features.

\section{RESULTS AND DISCUSSION}

The aluminium-zinc-magnesium alloys are well known(Mondolfo, 1976; Pugh and Jones, 1961) to form precipitate.-free zones(PFZ) on either sides of the and boundaries on ageing. Formation of PFZ can, to a certain extent, be prevented by the addition of metals like silver. In the high strength Al-Zn-Mg al under investigation here. PFZ were clearly visible in the aged $A 7-\mathrm{Zn}-\mathrm{Mg}$ alloy

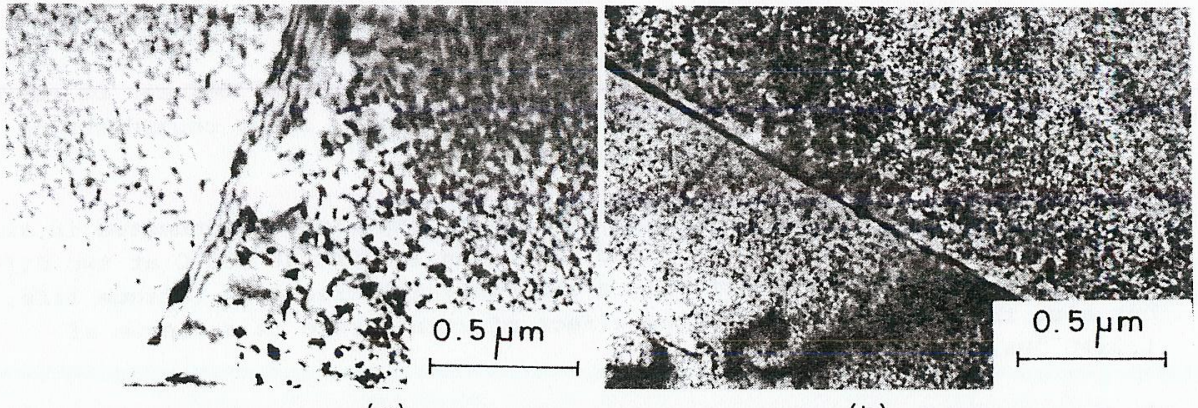

(a)

(b)

Fig. 1. Transmission electron micrograph of (a) base alloy and (b) beryllium-containing alloy showing presence of PFZ in (a) and its absence in (b)

1. (a). Addition of beryllium in trace amounts removed the PFZ nearly completely as shown in Fig. 1. (b). Also the presence of beryllium decreased the density of grain boundary precipitates indicating a retarded growth of the precipitates. Microstructures shown in Fig. 1. are for the peak-aged condition and were typical of observations made for all other ageing conditions.

The dynamic SCC behavior in air and in $3.5 \% \mathrm{NaCl}$ studied in different heattreated conditions and at different strain rates indicated a clear influence brought about by the addition of beryllium. The variation in the UTS of the two alloys as a function of ageing time is plotted in Fig. 2. A similar variation in the per cent reduction in area is plotted in Fig. 3. The effect of strain rate is also brought about in these plots. It is observed that in general increasing the strain rate leads to a reduction in the UTS and per cent reduction in area for a 77 treatments. A better comparison results by considering the variation in the fracture energy values. In Fig. 4 is shown
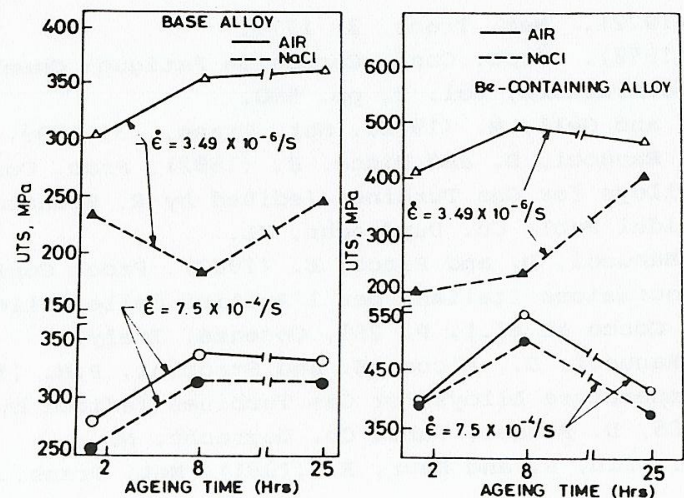

Fig. 2. Variation in the values of UTS as a function of strain rate and ageing time. 

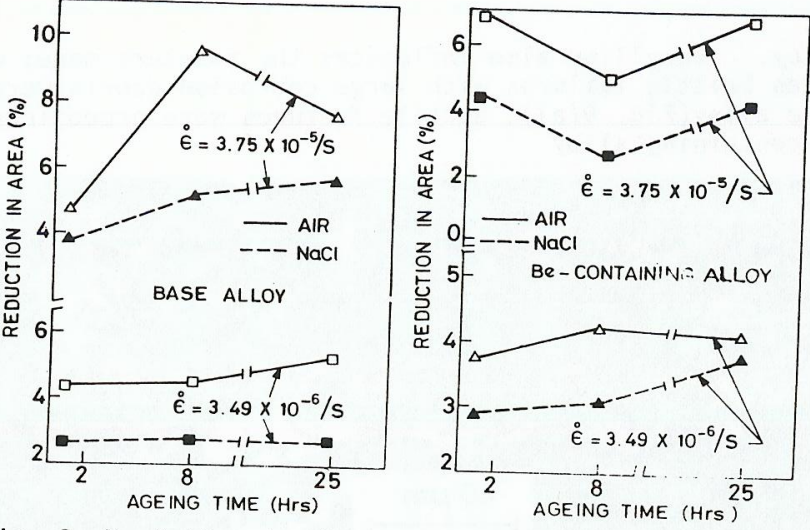
Fig. 3. Variation in the value of $\%$ reduction in area as a function
of strain rate and ageing time.

the variation of the ratio of fracture energy measured in the $3.5 \% \mathrm{NaCl}$ environment to that measured in air as a function of strain rate. This ratio was higher for base alloy than for the beryllium-containing alloy at all strain rates and for all heat treatments. Also in the base alloy it increased conticondition. In the over-aged with strain rat the ratio initially decreased than strain rate and then showed an increase so that for strain rates greater aged conditions than for the over-ags greater for the peak-aged and underconditions the higher strength peaked condition. Thus under dynamic SCC

if beryllium is present in the alloy. It is also noticits a better resistance

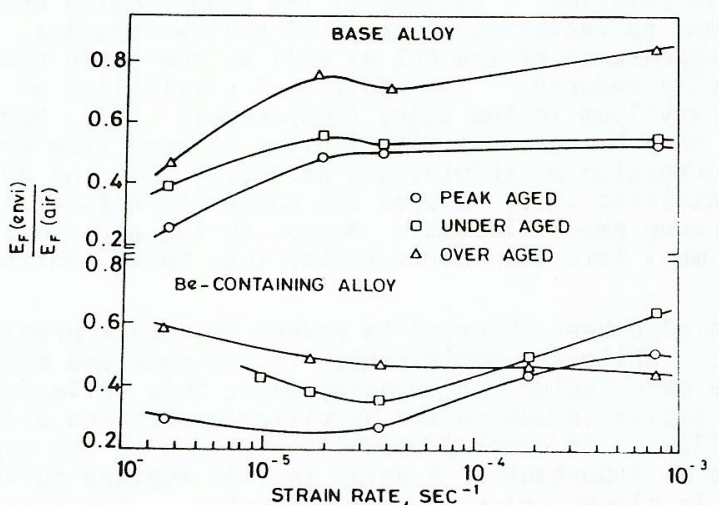

Fig. 4. Effect of strain rate on the ratio of fracture energy measured in $3.5 \% \mathrm{NaCl}$ to that measured in air for different heat treated conditions. strain rate of $2 \times 10^{-4} \mathrm{sec}-1$ the behavior in all the heat treated conditons
is the same. It was also observed that the influence becomes stronger as the solutionizina temperature is increased. This is understandable as the solubility of beryllium in the aluminium matrix increases with temperature rather steeply(Hansen and Anderko, 1958).

The influence of the presence of beryllium is also observed on the fracture surface in terms of the fractographic features. In Fig. 5 and Fig. 6 are shown the secondary electron images of fractured surfaces in the two alloys tested at two different strain rates. From these it is evident that in the alloys a ductile rupture is observed for high strain rates of testing while at lower strain rates a brittle intergranular failure results.

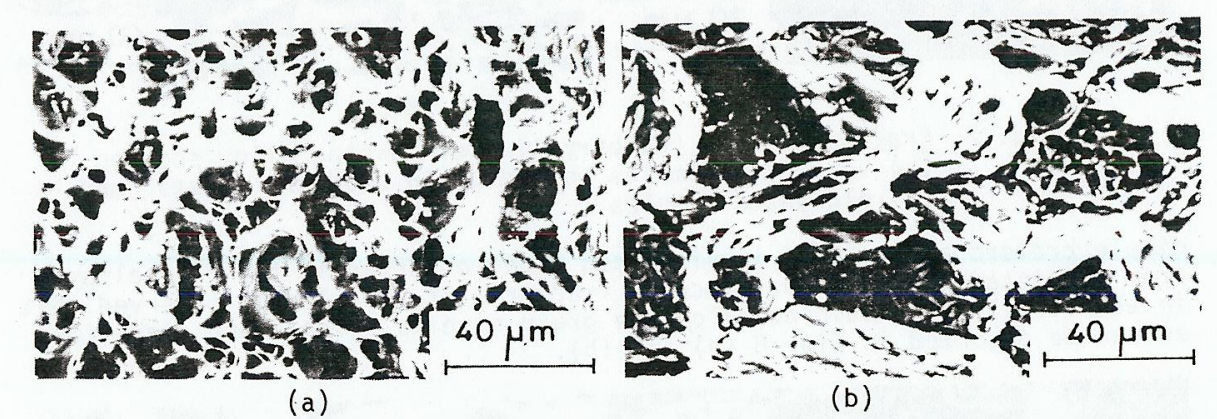

Fig. 5. Secondary electron images of fractures in specimens tested at a strain rate of $7.5 \times 10^{-4} \mathrm{sec}^{-1}$ ( (a) base alloy showing ductile dimples: (b) beryllium-containing alloy showing an intergranular ductile failure.

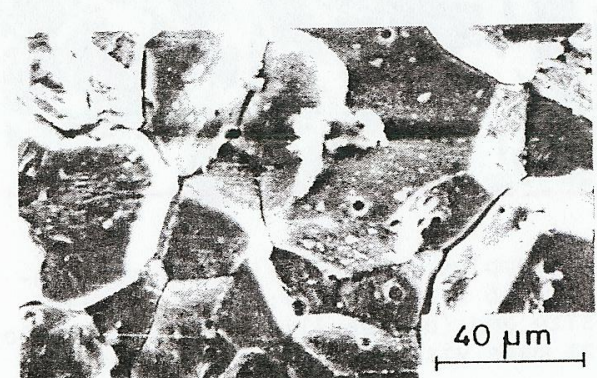

(a)

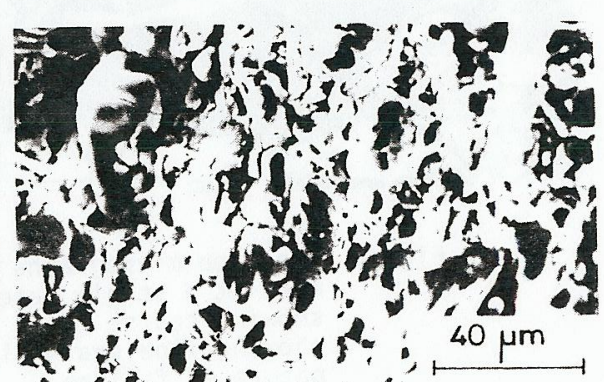

(b)
Fig. 6. Secondary electron fractographs of specimens tested at a a strain rate of $3.5 \times 10^{-6} \mathrm{sec}^{-1}$; (a) base alloy showing brittle intergranular failure; (b) beryllium containing alloy showing ductile failure features.

On a comparative basis the beryllium-containing alloy exhibits a greater amount of ductile features at all strain rates of testing. Even when the failure is intergranular the grain boundary surface is filled with a large number of very 
Also, the dimples in the of an intergranular ductile failure(Fig. 7(a)) (Fig. $7(b)$ ). The presence of precipitaining alloy appear rather elongated

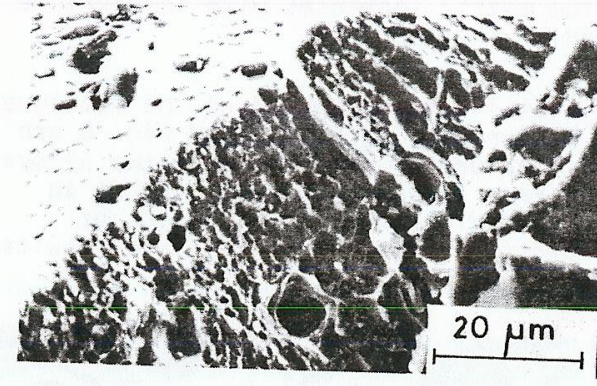

(a)

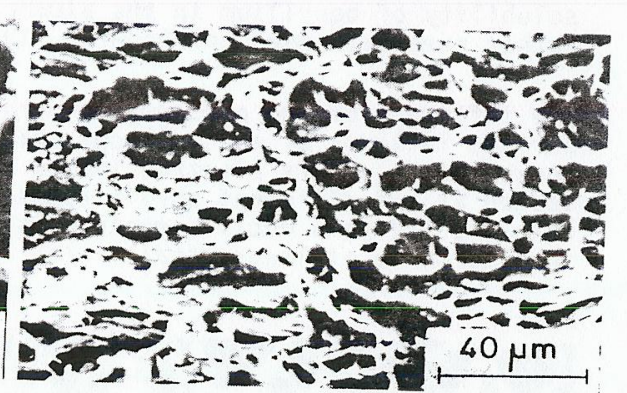

(b)
Fig. 7. Fractographs of the beryllium-containing alloy showing (a) very fine dimples on the grain boundary facets. and dimple craters are smaller in size than those observed in the base alloy. as can be observed in Fig. $8(a)$ and (b).

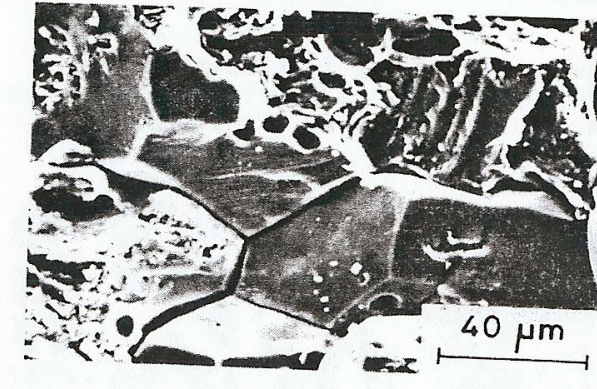

(a)

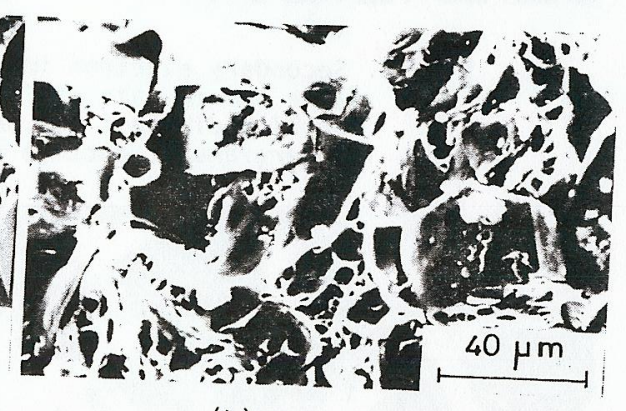

(b)
Fig. 8. Electron micrographs of samples fractured in $\mathrm{NaCl}$ environment at a strain rate of $3.5 \times 10^{-6} \mathrm{sec}^{-1}$; (a) base al showing fine grain size made visibleryllium-containing alloy showing fine grain size made visible by the intergranular

Results presented above can now be used to correlate the SCC behavior with the effects of changes in solute concentration near the grain boundary with and the consequent changes in the morphology of precipitates brought about by the trace addition. The base alloy exhibits a nearly continuous about boundary precipitate with a wide PFZ(Fig. 1(a)) whereas in the beryl grain containing alloyPFZ is absent for all the ageing periods (Fig. 1(b)). Addi tion of beryllium also decreases the number of grain boundary precipitates thereby increasing the interparticle spacing. Thus the preferentially corrod baths would be large but widely spaced in the presence of beryllium in the alloy. Beryllium also influences the fracture mode; while at low strain rates brittle failures with large corrosion debris were exhibited by the base alloy(Fig. 9(a)), ductile features were predominent in the

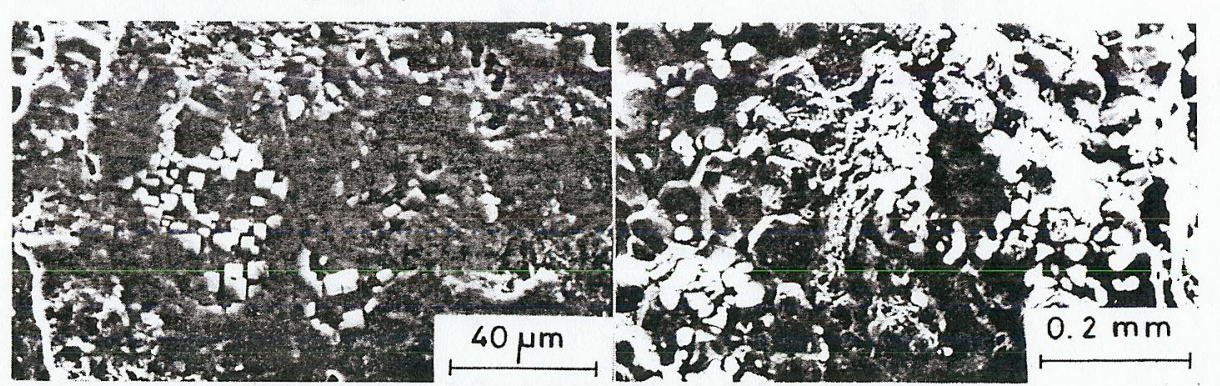

(a)

(b)

Fig. 9. Fractographs of samples tested in the $\mathrm{NaCl}$ environment at a strain rate of $3.5 \times 10^{-6} \mathrm{sec}^{-1}$. (a) base alloy showing heavy damage due to corrosion attack and the debris (b) beryllium-containing alloy showing predominently ductile features on an otherwise intergranular failure.

The solubility of beryllium in the aluminium alloy matrix is considered to be an important factor which greatly influences the SCC behavior of the alloy. The solid solubility of beryllium in aluminium(Hansen and Anderko, 1958) is ca. $0.5 \%$ at the eutectic temprature of $6450 \mathrm{C}$ and decreases to less than $0.01 \%$ at $500^{\circ} \mathrm{C}$ and less than $0.001 \%$ at room temperature. When quenched from the solutionizing temperature above $500^{\circ} \mathrm{C}$, a larger quantity of beryllium would be retained in solution. Because of the high binding energy exhibited by matrix are both pitation of beryllium in the al loy (Dwal possibility of independent preciresults in a very homogeneous distribution of very fin Narendranath, 1980) decreased segregation of solutes and particles beryllium containing alloy reduces the number of active sites for SCC in the possible hydrogen embrittlement. Hence during deformation strain fields are extended well into the matrix rather than being confined to the narrow PF7.

Beryllium has also been observed to reduce the crack propagation rates(Chandra-sekar, 1973). While the modification in the mode and morphology of precipitation is the main factor for bringing about this influence, several other factors also assist in making the beryllium-containina alloy more resistant the repassivating film at the crack tip is important. A delay in film rupture during slow straining could result in slower crack propagation rates. The ductility of the would would be reduced. This follows directly from the crack possess low stress concentration factors (Forrest 1962 ) that ductile materials probabily of plastic dissolution and hydrogen entry are slowed down to result in lower crack propagation rates. 
1344

SUMMARY

Addition of trace amounts of beryllium to high strength $\mathrm{A} 1-\mathrm{Zn}-\mathrm{Mg}$ compositions distribution and formation. The the through modification of precipitate

gation are greatly enhanced as a consequence. to dynamic SCC and to crack prope:

\section{REFERENCES}

Busby, J., Cleam, J. C. and Cudd, R.C. (1971). J. Inst. Metals, 99, 419 Ph.D. Thesis, Indian Inst Behavior of Age Hardened A7-Zn-Mg A7loys, Davies,

Day, M. K. B. Cornish Al Jurgica, 77, 51

Dwarakadasa, E. S. (1970). Jiusteringt, T. P. (1969). Met. Sci. J., 3, 174

Aluminium-Zinc-X Alloys, Ph.D. Thesis. Ind Solute Vacancy Interactions in

Forrest, P. G. (1962). Fatigue. Thesis, Ind. Inst. Sci.

Hansen, M. and Anderko, K. (1958) Constitutiomon Press, London.

Book Co., New York. Latanson, $R$. W and Stan Stahele, R. W. 'Forty, A. J: and Van Rooyen, D., NACE, Huston Texas, Eds.
Mondolfo, L. F. (1976). Butterworths, London.

teristics of $A 7-5 \mathrm{Zn}-4 \mathrm{M})$. Age Hardening, Deformation and Fracture CharacThesis, Ind. Inst Sci. Parkins, R. N. (1964). M. Mater. Sci., 5, 102

Peters, B. C. (1971). J. Inst Met 201.

Polmear, 1. J. (1960). J. Austr. Inst, 354.

Polmear, I. J. and Sargent, K. R. (1963). , 89, 19.

Pugh, E. N. and Jones, W. R. D. (1961), Nature, 200, 669

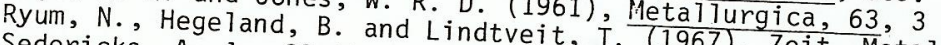

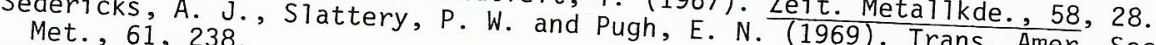
Themas, 61, 238.

Truscott, J. M. Nutting, J. $(1959-60)$. J. Inst. Met., 88, 81

Truscott, J. M. and Caivert, D. S. (ig67). Inst. Met., 88, 81. 81. 